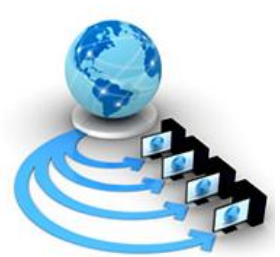

Volume 11, No. 1, January-February 2020

International Journal of Advanced Research in Computer Science

RESEARCH PAPER

Available Online at www.ijarcs.info

\title{
MEDICAL DIAGNOSIS USING NEUTROSOPHIC SOFT MATRICES AND THEIR COMPLIMENTS
}

\author{
Muhammad Naveed Jafar, Raiha Imran, Sabahat Hassan Asma Riffat \&Rubina Shuaib \\ Department ofMathematics \\ Lahore Garrison University \\ Lahore Pakistan
}

\begin{abstract}
Neutrosophic soft set is a mathematical technique to solve the uncertainties and imprecisions and for decision making problems. In this paper, it is intended to use Neutrosophic soft relations and compliments for medical diagnosis. This paper deals with the symptoms, patients and diseases and then by using compliment algorithm to diagnose the disease.
\end{abstract}

Keywords: Medical Diagnosis, Soft Set, Neutrosophic Soft Matrices, Compliment of NSS.

\section{INTRODUCTION}

There are many phases oflife in which we face the Uncertainty, Vagueness, complexities and unpredictability. Numerous complexities in engineering, financial, societal disciplines, therapeutic fields and numerous different arenas include provisional information. All such issues, a person comes to confront within life, cannot be illuminated utilizing traditional mathematical techniques. In traditional arithmetic, a numerical model of an entity is created and concept of particular elucidation of this classical paradigm is resolved. Therefore, the numerical model is excessively mind boggling, the particular result can't be found. To resolve these complexities many theories were introduced namely Probability theory, Fuzzy set theory introduced by LotfiZadeh in 1965[20]. Interval valued fuzzy set (IVFS) in 1975[21], Rough set theory developed by Z.Pawlak in 1982[10, 11],Intuitionistic sets were introduced by KassimirrAtanassov in 1983 [7], Neutrosophic sets were proposed by Smarandachein 1998 [18, 19] It is more powerful deals with truthiness, indeterminacy and falseness which exist in the real world. As in uncertain environment decision making is very complex issue so to resolve this issue D. Molodtsov presented Soft set theory in 1999[8].In 2010, Intuitionistic fuzzy matrices have been derived by Maji.et.al[9] use these terms for decision making.Jafar et al (2019) [2] use soft matrices to disease identification, in this paper we enhance the same work and use Neutrosophic soft matrices relations and their complement for the purpose of medical diagnosis. Neutrosophic sets gives more accurate results then fuzzy or intuitionistic sets. Neutrosophic sets based on Truthiness, Indeterminacy and falseness due to these factors it give more imprecise and accuracy in results. Many researchers [3-6, and 12-17]has work on decision making using soft sets and their relative concepts.
Fuzzy set [2]

If $X$ is a universal setand $x_{1} \in X$, then a fuzzy set Bdefined as $\lambda: B \rightarrow[0,1]$ such that

$\mathrm{B}=\left\{\left(x_{1}, u_{\lambda}\left(x_{1}\right)\right), x_{1} \in X\right\}$

Soft Set [2]

LetŨbe universal set and $\mathrm{E}_{\boldsymbol{c}}$ is the set of attributes. Let $\mathrm{P}(\tilde{\mathrm{U}})$ represents power set of $\tilde{\mathrm{U}}$ and $\tilde{\mathrm{A}} \subseteq$ E, a pair $(\breve{\mathrm{g}}, \mathrm{B})$ is called a soft set overU, where $f$ is a mapping defined by $f: B \rightarrow P(\tilde{U})$

Fuzzy Soft Set [2]

The pair $(\Lambda, \dot{\varepsilon})$ is called a FSS over ÿ, where $\Lambda: \dot{\varepsilon} \rightarrow \mathrm{P}(\ddot{y})$ defined a mapping from $\varepsilon$ into $\mathrm{P}(\mathrm{y})$. In fuzzy soft set we give fuzzy numbers to each alternative.

Intuitionistic Fuzzy Set [4]

Let $\tilde{U}$ be the universal set and $\mathrm{E}$ is the set of attributes. IFS

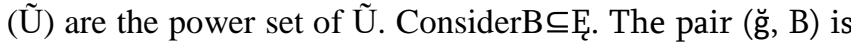
an IFS overŨ where $f$ is the mapping defined by $\mathrm{g}: \mathrm{B} \rightarrow$ IFS (U).

Neutrosophic Set [5]

A set $B$ that deals with the order triplet contains the degree of truthiness (T), indeterminacy (I) and falseness $(\mathrm{F})$ value. All Neutrosophic sets of B denoted by $F_{N}(B)$.

$B: E \rightarrow[0,1] \times[0,1] \times[0,1]$

\section{Neutrosophic Soft Set [5]}

Let $\tilde{U}$ be a universal set andE be a set of attributes and $\mathrm{B} \subseteq \mathrm{E}$, and then the set $(\breve{\mathrm{g}}, \mathrm{B})$ is known as NSS over $\hat{\mathrm{U}}$, where $\breve{\mathrm{g}}$ is a mapping defined by $\breve{\mathrm{g}}$ : $\mathrm{B} \rightarrow \breve{\mathrm{g}}_{\mathrm{N}}(\mathrm{B})$.

\section{Complement of NSS [4]}

The complement of NNS is defined as $\left(\breve{g}^{\mathrm{c}} \rightarrow \mathrm{B}\right)$ where $\breve{\mathrm{g}}^{\mathrm{c}}$ : $\mathrm{B} \rightarrow \breve{\mathrm{g}}_{\mathrm{N}}(\mathrm{X})$, and $\breve{\mathrm{g}}^{\mathrm{c}}\left(\mathrm{b}_{1}\right)=\left\langle\mathrm{x}_{1}, T_{\breve{\mathrm{g}}} c\left(x_{1}\right)=F_{\breve{\mathrm{g}}}\left(x_{1}\right), I_{\breve{g}_{\mathrm{g}}} c\left(x_{1}\right)=1-\right.$ $\mathrm{I}_{\breve{g}}\left(x_{1}\right), F_{\breve{g}} c\left(x_{1}\right)=\mathrm{T}_{\breve{\mathrm{g}}}\left(x_{1}\right)>$ for all $\mathrm{b}_{1} \in \mathrm{B}, x_{1} \in \mathrm{X}$. 
Neutrosophic soft matrices deals with the order triplet contains the degree of truthiness (T), indeterminacy (I) and falseness $(F)$ value, in matrices form.

\section{PRODUCT OF MATRICES}

Let $\mathrm{Y}$ be a nonempty set and

$\mathrm{B}=\left\langle x_{1}, \mathrm{~T}_{\mathrm{b}}\left(x_{1}\right), \mathrm{I}_{\mathrm{b}}\left(x_{1}\right), \mathrm{F}_{\mathrm{b}}\left(x_{1}\right)\right\rangle, \mathrm{E}=<x_{2}, \mathrm{~T}_{\mathrm{e}}\left(x_{2}\right), \mathrm{I}_{\mathrm{e}}\left(x_{2}\right), \mathrm{F}$ $\mathrm{e}\left(x_{2}\right)>$ be the neutrosophic fuzzy sets.

$\mathrm{BvE}=<\mathrm{x}, \mathrm{s}_{\mathrm{s}}\left(\mathrm{T}_{\mathrm{b}}\left(x_{1}\right), \mathrm{T}_{\mathrm{e}}\left(x_{2}\right)\right)$, average $\left(\mathrm{I}_{\mathrm{b}}\left(x_{1}\right), \mathrm{I}_{\mathrm{e}}\left(x_{2}\right)\right), \mathrm{t}(\mathrm{F}$ $\left.\mathrm{b}\left(x_{1}\right), \mathrm{F}_{\mathrm{e}}\left(x_{2}\right)\right)>$

$\mathrm{B} \wedge \mathrm{E}=\left\langle\mathrm{x}, \mathrm{t}\left(\mathrm{T}_{\mathrm{b}}\left(x_{1}\right), \mathrm{T}_{\mathrm{e}}\left(x_{2}\right)\right)\right.$, average $\left(\mathrm{I}_{\mathrm{b}}\left(x_{1}\right), \mathrm{I}_{\mathrm{e}}\left(x_{2}\right)\right)$, s $\left(\mathrm{F}_{\mathrm{b}}\left(x_{1}\right), \mathrm{F}_{\mathrm{e}}\left(x_{2}\right)\right)>$

\section{Relations on NSS [4]}

Let $\hat{H} \subseteq \mathrm{B} \times \mathrm{E}$. Then a NSS relation R between two NSS $(\breve{\mathrm{g}}, \mathrm{B})$ and $(\mathrm{g}, \mathrm{E})$ is defined by $\mathrm{R}_{1}\left(\mathrm{~b}_{1}, \mathrm{e}_{1}\right)=\breve{\mathrm{g}}\left(\mathrm{b}_{1}\right) \wedge \mathrm{g}\left(\mathrm{e}_{1}\right)$ for all $\mathrm{b}_{1} \in \mathrm{B}, \mathrm{e}_{1} \in \mathrm{E}$, where $\mathrm{R}_{1}: \hat{\mathrm{H}} \rightarrow \mathrm{Gn}(\tilde{\mathrm{U}})$

\section{EVALUATION OF NSS}

Let $(\breve{\mathrm{g}}, \mathrm{B})$ be NSS. Then the function $(\breve{\mathrm{g}}, \mathrm{B})$ is defined as Đ $(\breve{g}, B)=T_{b}+\left(1-I_{b}\right)-\breve{g}_{b}$, where $T_{b}, I_{b}$ and $\breve{g}_{b}$ denotes the truthiness, indeterminacy and falseness value of $(\breve{\mathrm{g}}, \mathrm{B})$ respectively.

\section{ALGORITHM AND METHODOLOGY}

Here, we describe a process used for medical diagnosis by NSS. Suppose that a set of patients is $\mathrm{P}^{\circ}$, set of symptoms $\check{\mathrm{S}}$ and the set of diseases is D.

\section{ALGORITHM}

i. The set of diseases related to its symptoms is obtained the symptoms-diseases relation $\mathrm{R}_{1}$

ii. The patient symptoms set is obtained the patient symptoms relation $\mathrm{Q}_{1}$

iii. Evaluate their corresponding complement matrices $\mathrm{R}_{2}$ and $\mathrm{Q}_{2}$

iv. The relation of patient symptoms disease matrices is $\mathrm{T}_{1}$

v. Compute relation $\mathrm{T}_{2}$ called patient non-symptoms non-disease matrices.

vi. Evaluate $\check{S}_{T_{1}}$ and $\check{S}_{T_{2}}$ NSS by using definition of "evaluation of NSS"

vii. Compute $\check{S}_{\mathrm{k}}$ i.e. Higher value of possibility of patient suffer with that disease

\section{CASE STUDY}

Assume that the three patients $\mathrm{P}_{1}, \mathrm{P} 2, \mathrm{P} 3$ in hospital with symptoms headache, temperature and severe pain is represented by $\mathrm{c}_{1}, \mathrm{c} 2, \mathrm{c} 3$. Now consider $\mathrm{P}=\left\{\mathrm{P}_{1}, \mathrm{P} 2, \mathrm{P} 3\right\}$ represents the patient and

$\check{\mathrm{S}}=\left\{\mathrm{c}_{1}\right.$, ç2, ç3 $\}$ shows the symptoms and set $\mathrm{D}=\left\{\mathrm{d}_{1}, \mathrm{~d}^{\prime} 2\right.$, d'3 $\}$ shows the diseases like fever, typhoid and malaria.

According to our data, we construct symptoms-diseases relation $\mathrm{R}_{1}$ and patient- symptoms relation $\mathrm{Q}_{1}$.

$$
\begin{array}{r}
\hat{R_{1}}=\left[\begin{array}{ccc}
(0.3,0.2,0.4) & (0.4,0.1,0.3) & (0.5,0.1,0.3) \\
(0.7,0.1,0) & (0.6,0,0.1) & (0.4,0.2,0.1) \\
(0.1,0.5,0.3) & (0,0.4,0.3) & (0,0.6,0.2)
\end{array}\right] \\
\mathrm{Q}_{1}=\left[\begin{array}{ccc}
(0,0.5,0.2) & (0.4,0.2,0.1) & (0.3,0.4,0.1) \\
(0.5,0.2,0.3) & (0.6,0.1,0.4) & (0.2,0.3,0.5) \\
(0.7,0.2,0.1) & (0.1,0.3,0.6) & (0.3,0.5,0.1)
\end{array}\right]
\end{array}
$$

The complement of $\hat{\mathrm{R}_{1}}$ and $\mathrm{Q}_{1}$ is represented by $\hat{\mathrm{R}_{2}}$ and $\mathrm{Q}_{2}$ respectively.

$$
\begin{aligned}
\hat{R_{2}} & =\left[\begin{array}{ccc}
(0.4,0.8,0.3) & (0.3,0.9,0.4) & (0.3,0.9,0.5) \\
(0,0.9,0.7) & (0.1,1,0.6) & (0.1,0.8,0.4) \\
(0.3,0.5,0.1) & (0.3,0.6,0) & (0.2,0.4,0)
\end{array}\right] \\
\mathrm{Q}_{2} & =\left[\begin{array}{ccc}
(0.2,0.5,0) & (0.1,0.8,0.4) & (0.1,0.6,0.3) \\
(0.3,0.8,0.5) & (0.4,0.9,0.6) & (0.5,0.7,0.2) \\
(0.1,0.8,0.7) & (0.6,0.7,0.1) & (0.1,0.5,0.3)
\end{array}\right]
\end{aligned}
$$

Here $\mathrm{R}_{2}$ represents the non-symptoms disease matrix and $\mathrm{Q}_{2}$ represents the patient non-symptoms matrix. As we have

$$
\begin{aligned}
\mathrm{T}_{1}= & \mathrm{Q}_{1} \mathrm{R}_{1}= \\
& {\left[\begin{array}{lcc}
(0.4,0.4,0.1) & (0.4,0.4,0.1) & (0.5,0.5,0.1) \\
(0.6,0.4,0.1) & (0.4,0.15,0.3) & (0.5,0.15,0.3) \\
(0.3,0.5,0.3) & (0.4,0.15,0.3) & (0.5,0.55,0.3)
\end{array}\right] } \\
\mathrm{T}_{2}= & \mathrm{Q}_{2} \mathrm{R}_{2}= \\
& {\left[\begin{array}{lll}
(0.2,0.85,0.3) & (0.2,0.9,0.3) & (0.2,0.8,0.3) \\
(0.3,0.9,0.2) & (0.3,0.95,0.2) & (0.3,0.85,0.2) \\
(0.1,0.8,0.3) & (0.1,0.85,0.3) & (0.1,0.85,0.3)
\end{array}\right] }
\end{aligned}
$$

Now calculate $\check{S}_{T_{1}}$ and $\check{S}_{T_{2}}$ of Neutrosophic fuzzy set

$$
\begin{aligned}
& \check{S}_{T_{1}}=\left[\begin{array}{ccc}
0.9 & 0.9 & 0.9 \\
1.1 & 0.95 & 0.55 \\
0.5 & 0.95 & 0.65
\end{array}\right] \text { and } \\
& \check{S}_{T_{2}}=\left[\begin{array}{ccc}
0.05 & 0 & 0.1 \\
0.2 & 0.15 & 0.25 \\
0 & -0.05 & -0.05
\end{array}\right] \\
& \check{S}_{\mathrm{k}}=\check{S}_{T_{1}}-\check{\mathrm{S}}_{T_{2}}=\left[\begin{array}{ccc}
0.85 & 0.9 & 0.8 \\
0.9 & 0.8 & 0.3 \\
0.5 & 1 & 0.7
\end{array}\right]
\end{aligned}
$$

From the result, this is the highest possibility that patient suffer from that disease

\section{CONCLUSION}

We have executed the idea of NSS for medical diagnosis. The result $\check{S}_{\text {s }}$ shows the highest possibility that patient suffer from that disease. It is an approach to evaluate which patient is affected from what disease. By using Neutrosophic fuzzy soft sets we can solve other decision making problems. 


\section{REFERENCES}

[1] AkhilRanjanRoy,PK Maji, A fuzzy soft set theoretic approach to decision making problems, Journal of Computational and Applied Mathematics 203 (2), 412-418,2007

[2] Jafar.N.M, Muniba.K, Saeed.A, Abbas.S,Bibi.I (2019). Applications of Sanchez, Approach in Medical Diagnosis using Trapezoidal Fuzzy Numbers. International Journal of Latest Engineering, Research and its Applications .4 (9): 5157.

[3] Jafar.N.M, Saqlain.M, Saeed.M, Abbas.Q (2020), Application of Soft-Set Relations and Soft Matrices in Medical Diagnosis using Sanchez's Approach , International Journal of Computer Applications, 177(32): 7-11.

[4] Jafar.N.M, Faizullah, Shabbir.S, Alvi.F.M.S, Shaheen.L (2020), Intuitionistic Fuzzy Soft Matrices, Compliments and Their Relations with Comprehensive Study of Medical Diagnosis, International Journal of Latest Engineering Research and Applications, 5(1): 23-30.

[5] Jafar.N.M, Saeed.A, Waheed.M, Shafiq.A (2020), A Comprehensive Study of Intuitionistic Fuzzy Soft Matrices and its Applications in Selection of Laptop by Using Score Function, International Journal of Computer Applications, 177(38): 8-17.

[6] Jafar.N.M, Khan.R.M, Sultan.H, Ahmad.N (2020), Interval Valued Fuzzy Soft Sets and Algorithm of IVFSS Applied to the Risk Analysis of Prostate Cancer, International Journal of Computer Applications, 177(38): 18-26.

[7] K.Atanassov, G.Gargov interval valued intuitionistic fuzzy sets, fuzzy sets Syst. 31(1989) 343-349.

[8] Molodtsov D. Soft set theory-first result. Computers and Mathematics with Applications. 1999; 37:19-31.

[9] Maji PK, Biswas R, Roy AR. Fuzzy soft set. The Journal of Fuzzy Mathematics. 2001; 9(3):677-692.

[10] Pawlak Z. Rough sets. Int. J. Inf. Comp. Sci. 1982; 11:341356.
[11] Pawlak Z. Rough classification, International Journal of ManMachine Studies 20(5), 469-483, 1984

[12] Riaz.M, Saeed.M, Saqlain.M, Jafar.N (2019), Impact of Water Hardness in Instinctive Laundry System Based on Fuzzy Logic Controller, Punjab University Journal of Mathematics, 51(4):73-84

[13] Saeed, M., Zulqarnain, M. and Dayan, F. (2018). TOPSIS analysis for the prediction of diabetes based on general characteristics of humans. Int. J. of Pharm. Sci. and Research. 9: 2932-2939

[14] Saqlain.M.Jafar.N, Riffat.A (2018), Smart Phone Selection by Consumers' In Pakistan: FMCGDM Fuzzy Multiple Criteria Group Decision Making Approach, Gomal University Journal of Research, 34 (1): 27-31.

[15] Saqlain.M, Jafar.N, Hamid.R,Shahzad.A. (2019), Prediction of Cricket World Cup 2019 by TOPSIS Technique of MCDM-A Mathematical Analysis, International Journal of Scientific \& Engineering Research, 10(2): 789-792

[16] Saqlain.M, Naz.K, Ghaffar.K, Jafar.N.M (2019), Fuzzy Logic Controller: The Impact of Water $\mathrm{pH}$ on Detergents, Scientific Inquiry of Review 3(3):16-29

[17] Saqlain M, Saeed M, Ahmad M.R, SmarandacheF, (2019), Generalization of TOPSIS for Neutrosophic Hypersoft set using Accuracy Function and its Application, Neutrosophic Sets and Systems (NSS), 27: 131-137.

[18] Smarandache F. Neutrosophy and Neutrosophic logic. First International Conference on Neutrosophy, Neutrosophic Logic, Set, Probability and Statistics. University of New Mexico, Gallup, USA; 2002.

[19] Smarandache F., Definition of Neutrosophic logic-a generalization of the Intuitionistic fuzzy logic, EUSFLAT Conf., 141-146, 2003

[20] Zadeh L.A. Fuzzy sets. Inf. Control. 1965; 8:338-353.

[21] ZadehL.A.Fuzzy sets as a basis for a theory of possibility, Fuzzy sets and system1 (1), 3-28, 1978. 